В.В. Федько

Харківський національний економічний університет ім. С. Кузнеия, Харків

\title{
ДОСЛІДЖЕННЯ ЕФЕКТИВНОСТІ ЗАСТОСУВАННЯ ТЕХНОЛОГІЇ МАСНINЕ LEARNING SERVICES В ЗАДАЧАХ ПРОГНОЗУВАННЯ
}

Викладено і проаналізовано результати експериметів щзодо ефективності розв'язання задач прогнозування методами Machine Learning із застосуванням технологї Machine Learning Services. Ця технологія полягає у перенесенні процесів оброблення даних з комп'ютера клієнта (як це реалізовано у класичній технологї̈ Machine Learning) на сервер, на якому зберігаються дані. Дослідження проводилися шляхом порівняння витрат часу розв'язання задач за кожною технологією при різних обсягах даних. Результати досліджень показали, щз застосування технологї̈ Machine Learning Services має у два рази кращі показники на кількості даних понад півтора мільйона записів.

Ключові слова: Machine Learning, сховище даних, SQL Server, Python, Machine Learning Services, продуктивність програми.

\section{Вступ}

Постановка проблеми. Методи машинного навчання (Machine Learning, скор. ML) посіли одне 3 важливих місць в аналізі даних, особливо в галузі Big Data [1-4]. Приклади використання методів ML розглянуто в [5-7]. Методи ML часто кладуть в основу побудови таких засобів візуалізації результатів аналізу даних як Dashboard [8-9]. У ньому дані згруповані за змістом для більш легкого візуального сприйняття інформації про бізнес-процеси за значною кількістю показників [10-12].

Реалізація аналізу даних в інтерактивному режимі накладає жорсткі обмеження на час, за який виконується перехід від одних значень параметрів аналізу до інших. Особливої гостроти проблема розв'язання задач в режимі реального часу набуває у разі, коли дані зберігаються в базах даних значних розмірів.

Аналіз останніх досліджень і публікацій. За останнє десятиріччя провідні методи аналізу даних були реалізовані мовами $\mathrm{R}$ та Python [13-14]. У класичному варіанті потрібні дані завантажуються 3 сервера бази даних на комп'ютер клієнта і вже тут обробляються. Розроблена корпорацією Microsoft технологія Machine Learning Services (MLS) спрямована на зменшення проблеми часу оброблення даних за рахунок перенесення його на сервер, на якому зберігаються дані. Цій тематиці присвячені роботи [15-17]. В них розглядають переваги застосування технології MLS на якісному рівні.

Мета статті. Робота спрямована на визначення ефективності застосування технології MLS у числовому вимірі шляхом порівняння з витратами часу на розв'язання тієї самої задачі з використанням класичної технології ML.

\section{Виклад основного матеріалу}

Для отримання кількісних показників ефективності використання технології MLS пропонується провести серію експериментів, в яких виконуються заміри часу на виконання розрахунків прогнозування даних на основі лінійної регресії методами ML безпосередньо на сервері бази даних при різній кількості вхідних даних. Для порівняння аналогічні заміри здійснюються 3 використанням класичного варіанту, коли оброблення даних виконується подібними програмами безпосередньо на комп'ютері клієнта 3 попереднім пересиланням різної кількості даних із сервера. Схеми виконання обчислень подано на рис. 1 i 2.

Етап оброблення даних традиційно складається 3 двох кроків - навчання та прогнозування. Вони реалізуються модулями 3 Руthon-бібліотеки scikitlearn [18]. Вибірка даних з бази здійснюється засобами СУБд SQL Server на основі мови SQL.

Під час проведення дослідів потрібно визначити час на пересилання даних і їхнє оброблення. Процес пересилання даних у класичній технології складається з таких етапів:

1) вибірка даних з бази, що розташована на жорсткому диску, і збереження в оперативній пам'яті сервера;

2) пересилання даних з сервера на комп'ютер клієнта.

В цілому вони складають час завантаження даних. Він $є$ значимим, оскільки пересилаються великі обсяги даних (мільйони записів і більше). Після цього здійснюється оброблення даних методами ML на комп’ютері клієнта. У технології MLS відсутній другий етап пересилання даних, оскільки дані обробляються на сервері. 


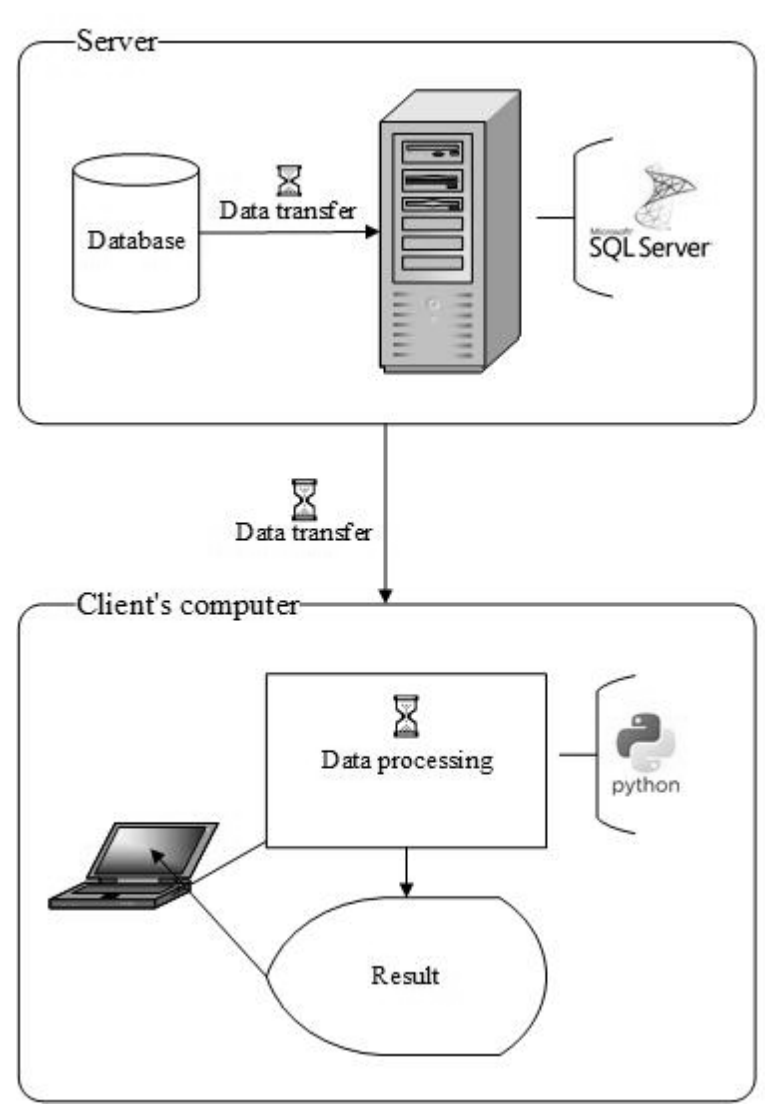

Рис. 1. Схема виконання обчислень методами ML з використанням класичної технології Джерело: розроблено автором за даними [17, C. 139].

Час пересилання результату не вимірюється, оскільки він $є$ незначним через малу кількість даних.

Завданням дослідження $є$ встановлення ефективності застосування технології MLS у порівнянні 3 класичною технологією за необхідними витратами часу на прикладі розв'язання модельної задачі прогнозування [18].

Для проведення досліджень створено базу даних і сховище даних, які близькі до тих, що описані в [14]. 3 метою збільшення кількості даних, до них додано ще один вимір - розглядається мережа кіосків, а не один кіоск. Така схема сховища даних дозволяє досить просто керувати кількістю даних у ньому. Якщо взяти по 10 значень у кожній таблиці вимірів DimKiosk, DimManufacturer та DimProduct, то у таблиці фактів буде майже 1000 записів за один день (не всі товари кожного виробника продавалися кожного дня). У дослідженнях бралися дані за період 2010 - 2021 p.p. (4 371830 записів у таблиці фактів).

Оскільки потрібно порівнювати час розв'язання задачі прогнозування за двома технологіями - класичною i MLS, які реалізуються мовами Python i SQL, в якості середовища розробки вибрано Azure Data Studio. Окрім інстументів роботи з базою даних воно дає можливість легко перемикатися 3 однієї мови на іншу. Цю опцію реалізують за рахунок можливості одночасного ведення кількох записних книжок Jupyter Notebook, кожна 3 яких підтрмує певну мову [20].

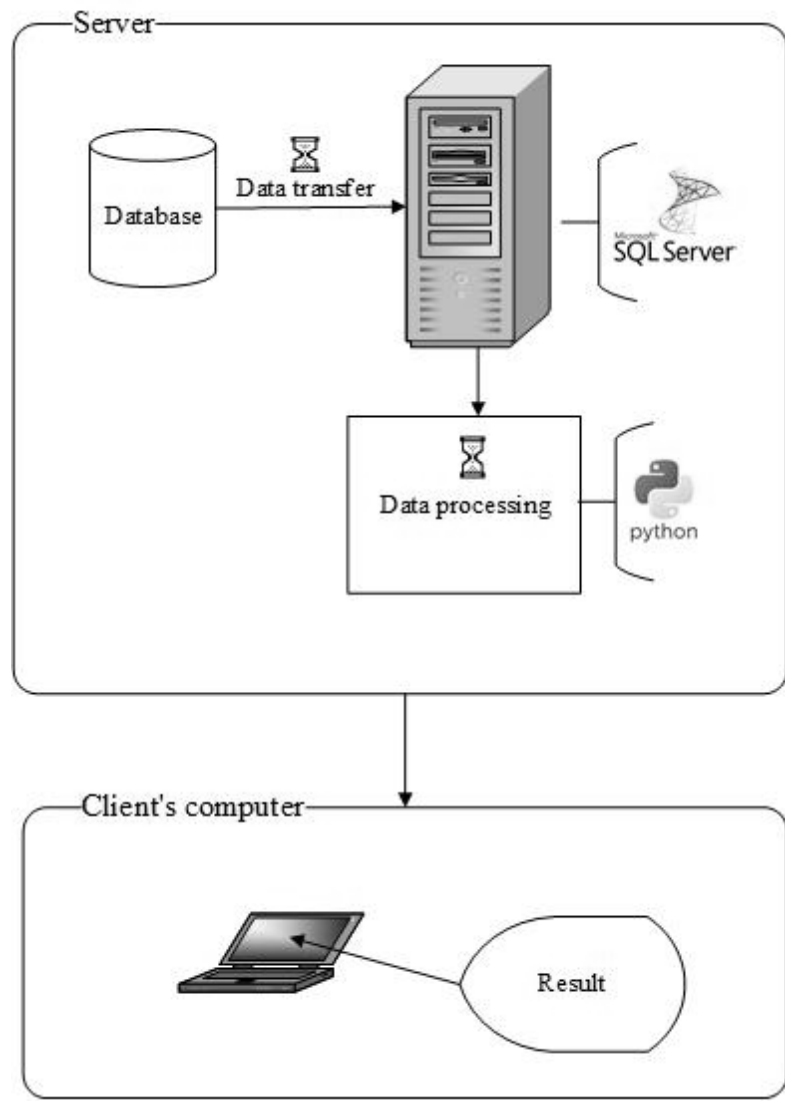

Рис. 2. Схема виконання обчислень методами ML з використанням технології MLS

Джерело: розроблено автором за даними [17, C. 139].

Час, потрібний для завантаження даних та їхнього оброблення, залежить від стану інших процесів, що одночасно протікають на комп'ютері. Тому для тієї самої кількості даних проводиться серія експериментів. У ній експеримент повторюється 10 разів, а потім обчислюються середні арифметичні значення, що отримані у серіі.

3 метою подальшого аналізу результати кожного експерименту заносяться в окрему таблицю TimeTest. Ïї схему подано на рис. 3.

\begin{tabular}{l|}
\hline TestTime \\
\hline TimeTestld \\
\hline Dateld \\
Env \\
CountRows \\
DataLoadTime \\
DataProcessingTime \\
\hline
\end{tabular}

Рис. 3. Схема таблиці TimeTest Джерело: розроблено автором.

Поля таблиці TimeTest мають таке призначення: 
DateId - ідентифікатор кінцевого року, дані до якого включно беруть участь в поточному експерименті;

Env - ідентифікатор технології (1 - класична, 2 - MLS);

CountRows - кількість рядків даних, що обробляються в експерименті;

DataLoadTime - час, витрачений на завантаження даних;

DataProcessingTime - час, витрачений на оброблення даних.

Для реалізації оброблення даних за класичною технологією розроблено Python-програму за сxемою, яку подано на рис. 1.

А для реалізації оброблення даних за технологією MLS розроблено збережену процедуру TestSQL за схемою, яку подано на рис. 2. Вона базується на попередній Python-програмі з використанням системної збереженої процедури sp_execute_external script [14].

Для організації серії викликань збереженої процедури TestSQL під час проведення експериментів за технологією MLS розроблено відповідний SQL-скрипт.

Для кожного експерименту у ньому передбачено фіксацію часу перед викликанням збереженої процедури TestSQL, обчислення досліджуваних параметрів і запис їх значень у таблицю результатів TimeTest.

У табл. 1 і 2 подано результати кожної серії експериментів, що отримані після обчислення середніх арифметичних витрат часу щодо кожної серії.

Таблиця 1

Усереднені результати експериментів оброблення даних

за класичною технологією

\begin{tabular}{|c|c|c|c|c|}
\hline Рік & $\begin{array}{c}\text { Кількість } \\
\text { записів, } \\
\text { млн } \\
\text { заванта- } \\
\text { ження } \\
\text { даних, } \\
\text { сек. }\end{array}$ & $\begin{array}{c}\text { Час } \\
\text { оброб- } \\
\text { лення } \\
\text { даних, } \\
\text { сек. }\end{array}$ & $\begin{array}{c}\text { Загальний } \\
\text { час, } \\
\text { сек. }\end{array}$ \\
\hline 2011 & 0.728207 & 5.289 & 0.345 & 5.634 \\
\hline 2012 & 1.093242 & 7.601 & 0.452 & 8.053 \\
\hline 2013 & 1.457353 & 12.016 & 0.669 & 12.685 \\
\hline 2014 & 1.821398 & 15.562 & 0.867 & 16.429 \\
\hline 2015 & 2.185438 & 18.737 & 1.019 & 19.756 \\
\hline 2016 & 2.550496 & 22.175 & 1.145 & 23.320 \\
\hline 2017 & 2.914573 & 19.700 & 1.141 & 20.841 \\
\hline 2018 & 3.278649 & 21.254 & 1.267 & 22.521 \\
\hline 2019 & 3.642714 & 23.121 & 1.405 & 24.526 \\
\hline 2020 & 4.007762 & 25.832 & 1.593 & 27.425 \\
\hline 2021 & 4.371830 & 28.111 & 1.706 & 29.817 \\
\hline
\end{tabular}

Джерело: розроблено автором.
Таблиця 2

Усереднені результати експериментів оброблення даних за технологією MLS

\begin{tabular}{|c|c|c|c|c|}
\hline Рік & $\begin{array}{c}\text { Кількість } \\
\text { записів, } \\
\text { млн }\end{array}$ & $\begin{array}{c}\text { Час заван- } \\
\text { таження } \\
\text { даних, } \\
\text { сек. }\end{array}$ & $\begin{array}{c}\text { Час } \\
\text { оброб- } \\
\text { лення } \\
\text { даних, } \\
\text { сек. }\end{array}$ & $\begin{array}{c}\text { Загальний } \\
\text { час, } \\
\text { сек. }\end{array}$ \\
\hline 2011 & 0.728207 & 4.142 & 0.217 & 4.359 \\
\hline 2012 & 1.093242 & 4.481 & 0.326 & 4.807 \\
\hline 2013 & 1.457353 & 4.766 & 0.446 & 5.213 \\
\hline 2014 & 1.821398 & 5.013 & 0.538 & 5.551 \\
\hline 2015 & 2.185438 & 5.478 & 0.648 & 6.126 \\
\hline 2016 & 2.550496 & 6.112 & 0.776 & 6.888 \\
\hline 2017 & 2.914573 & 6.419 & 0.886 & 7.305 \\
\hline 2018 & 3.278649 & 6.455 & 0.977 & 7.431 \\
\hline 2019 & 3.642714 & 6.852 & 1.093 & 7.945 \\
\hline 2020 & 4.007762 & 7.189 & 1.196 & 8.385 \\
\hline 2021 & 4.371830 & 7.567 & 1.280 & 8.847 \\
\hline
\end{tabular}

Джерело: розроблено автором.

Під час проведення експериментів здійнювалося спостереження за двома компонентами - часом завантаження даних і їхнього оброблення. Визначення значущості кожного компонента у загальних витратах часу у разі використання класичної технології, можна здійснити з аналізу кругових діаграм, поданих на рис. 4 і 5. Вони побудовані на даних 3 початку і кінця досліджуваного діапазону.

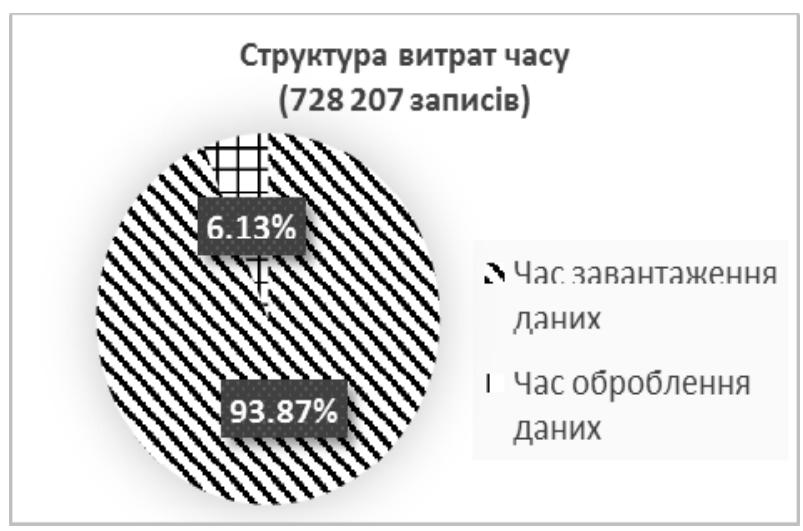

Рис. 4. Структура вират часу

(класична технологія, 728207 записів)

Джерело: розроблено автором.

3 рис. 4 та рис. 5 випливає, що у разі застосування класичної технології, час оброблення даних становить тільки $6 \%$ від загальних витрат часу, а основна частина часу припадає на завантаження даних. Аналогічна ситуація спостерігається у разі застосування технології MLS. Хоча частка, яка припадає на оброблення даних, тут дещо збільшується 
iз ростом кількості даних, що пояснюється відносним зменшенням часу на завантаження даних.

На кінцях досліджуваного діапазону кількості даних частка часу оброблення даних становить відповідно 4.99 \% (при кількості записів 728 207) i $14.47 \%$ \% (при кількості записів 4371 830).

Загальні витрати часу за кожною технологією подано на рис. 6. 3 нього випливає, що технологія MLS вимагає значно менше часу на розв'язання задач прогнозування методами ML у порівнянні 3 класичною технологією. Причому ця перевага має тенденцію до збільшення зі зростанням обсягів даних.

Про кількісні переваги технології MLS у порівнянні з класичною технологією у відсотках можна судити 3 аналізу діаграми, що подано на рис. 7. 3 нього випливає, що технологія MLS вимагає приблизно у два рази менше часу у порівнянні 3 класичною технологією.
Причому ця перевага значною мірою проявляється у разі, коли кількість записів є понад 1.5 млн. У разі меншої кількості даних ефект від застосування технології MLS є порівняно незначним.

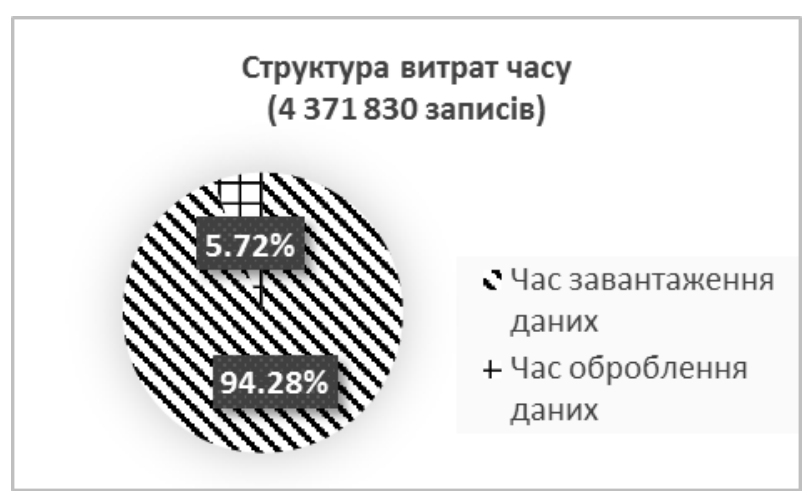

Рис. 5. Структура вират часу

(класична технологія, 4371830 записів)

Джерело: розроблено автором.

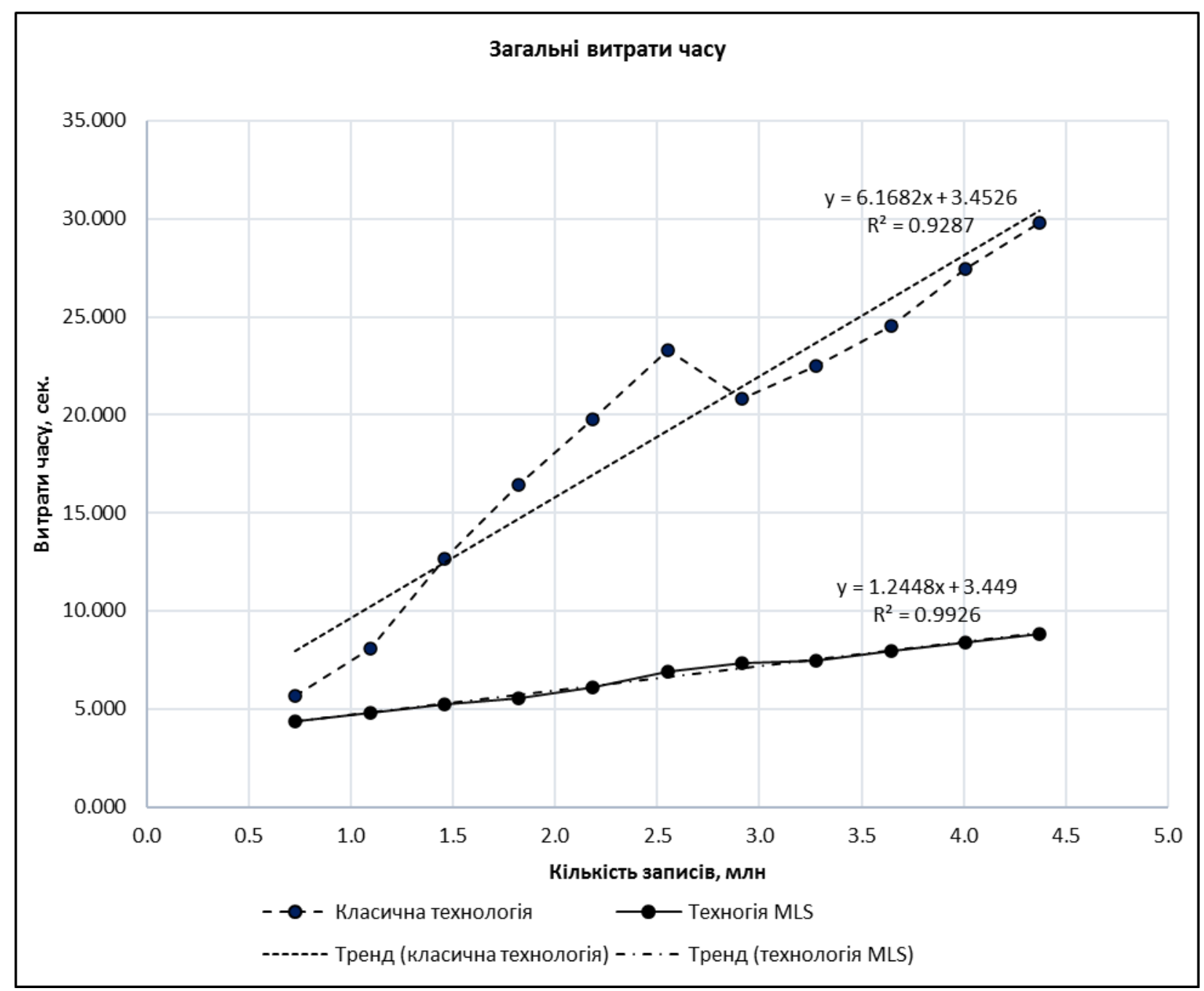

Рис. 6. Загальні витрати часу

Джерело: розроблено автором. 


\section{Переваги технології MLS}

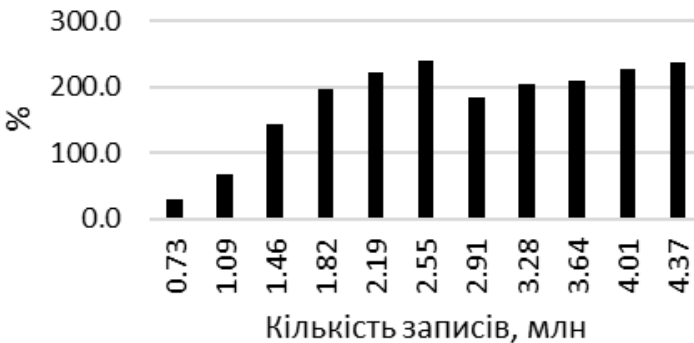

Рис. 7. Переваги технології MLS Джерело: розроблено автором.

\section{Висновки}

У роботі розлянуто результати досліджень витрат часу на розв'язання задач прогнозування методами ML у разі застосування технології MLS у порівнянні з класичною технологією.

Проведені дослідження показали:

1) загальний час розв'язання задач прогнозу- вання методами методами ML у разі застосування технології MLS в два рази коротший у порівнянні 3 класичною технологією;

2) значний виграш у часі проявляється, коли кількість записів перевищує 1.5 млн. У разі меншої кількості даних переваги $є$ незначними;

3) основний вклад у витрату часу розв'язання задач прогнозування методами ML припадає на передачу даних з бази даних на комп'ютер кліента;

4) витрати загального часу на розв'язання досліджуваних задач добре описується лінійною залежністю від кількості оброблюваних даних в обох технологіях, але в технології MLS він зростає у п'ять разів повільніше.

Дослідження проводилися в умовах, коли клієнт і сервер були розташовані на одному фізичному комп'ютері. Становлять інтерес подальші аналогічні дослідження, коли сервер знаходиться на віддаленому комп'ютері або у хмарах.

Отримані результати слід враховувати під час розроблення застосунків, що реалізують методи ML.

\section{Список літератури}

1. Quinlan J.R. C4.5: Programs for Machine Learning / J.R. Quinlan. - Burlington: Kaufmann Publishers, 1993. - 302 p.

2. Classification and regression trees / L. Breiman, J. Friedman, C.J. Stone, R.A. Olshen. - Boca Raton: CRC press, 1984. $368 \mathrm{p}$.

3. Fisher D.H. Knowledge acquisition via incremental conceptual clustering / D.H. Fisher // Machine learning. - 1987. № 2(2). - P. 139-172.

4. Аксютина Е.М. Обзор архитектур и методов машинного обучения для анализа больших данных [Электронный ресурс] / Е.М. Аксютина, Ю.С. Белов // Наука, техника и образование. - 2016. - № 1(5). - С. 132-139. - Режим доступа: http://nto-journal.ru/uploads/articles/0b9bd6d9833003ed0d6f9bb16fab81f1.pdf.

5. Machine learning facilitated business intelligence (Part I): Neural networks learning algorithms and applications / W.A. Khan, S.H. Chung, M.U. Awan, X. Wen // Industrial Management \& Data Systems. - 2019. - No. 120(1). - P. 164-195. https://doi.org/10.1108/IMDS-07-2019-0361.

6. Flight Delay Prediction Based on Aviation Big Data and Machine Learning / G. Gui, F. Liu, J. Sun, J. Yang, Z. Zhou, D. Zhao // IEEE Transactions on Vehicular Technology. $\quad-\quad 2020 . \quad-\quad № 69(1)$. $\quad$ P. 140-150. https://doi.org/10.1109/TVT.2019.2954094.

7. Canhoto A. Artificial intelligence and machine learning as business tools: A framework for diagnosing value destruction potential / A. Canhoto, F. Clear // Business Horizons, Elsevier - 2020. - № 63(1). - P. 183-193. https://doi.org/10.1016/j.bushor.2019.11.003.

8. Kurnia P.F. Business Intelligence Model to Analyze Social Media Information / P.F. Kurnia, Suharjito // Procedia Computer Science. - 2018. - № 135. - P. 5-14. https://doi.org/10.1016/j.procs.2018.08.144.

9. Multimodal social intelligence in a real-time dashboard system / Daniel Gruhl, Meena Nagarajan, Jan Pieper, Christine Robson, Amit Sheth // The VLDB Journal. - 2010. - № 19. - P. 825-848. https://doi.org/10.1007/s00778-010-0207-5.

10. Fundamentals of Business Process Management / Marlon Dumas, Marcello La Rosa, Jan Mendling, Hajo A Reijers. Berlin: Springer, 2013. - 399 p.

11. Henseler J. Using PLS Path Modeling in New Technology Research: Updated Guidelines / J. Henseler, G. Hubona, P.A. Ray // Industrial Management \& Data Systems. - 2016. - № 116(1). - P. 2-20. https://doi.org/10.1108/IMDS-09-2015-0382.

12. Cadle J. Business Analysis Techniques: 72 Essential Tools for Success / James Cadle, Debra Paul, Paul Turner. - New York: BCS, The Chartered Institute, 2010. -260 p.

13. Fischetti T. Data Analysis with R - Second Edition: A comprehensive guide to manipulating, analyzing, and visualizing data in R / T. Fischetti. - Birmingham: Packt Publishing, 2018. - 570 p.

14. Géron A. Hands-On Machine Learning with Scikit-Learn, Keras, and TensorFlow: Concepts, Tools, and Techniques to Build Intelligent Systems 2nd Edition / A. Géron. - Newton: O'Reilly Media, Inc., 2019. - 856 p.

15. Posey B. A closer look at Python-SQL Server 2017 integration [Electronic resource] / B. Posey. - Available at: https://searchsqlserver.techtarget.com/tip/A-closer-look-at-Python-SQL-Server-2017-integration.

16. Федько В.В. Аналіз даних в SQL Server засобами Python / В.В. Федько // Збірник наукових праць Харківського національного університету Повітряних Сил. - 2018. - № 2(5б). - С. 99-104. https://doi.org/10.30748/zhups.2018.56.14.

17. Etaati L. Using R with SQL Server 2016 and 2017. In: Machine Learning with Microsoft Technologies / L. Etaati. - 
Berkeley: CA, 2019. - P. 139-158. https://doi.org/10.1007/978-1-4842-3658-1_9.

18. Scikit-learn: Machine Learning in Python [Electronic resource]. - Available at: https://scikit-learn.org/stable/.

19. Python tutorial: Predict ski rental with linear regression with SQL machine learning [Electronic resource]. - Available at: https://docs.microsoft.com/en-us/sql/machine-learning/tutorials/python-ski-rental-linear-regression?view=sql-server-ver15.

20. Use Jupyter Notebooks in Azure Data Studio [Electronic resource]. - Available at: https://docs.microsoft.com/enus/sq1/azure-data-studio/notebooks/notebooks-guidance?view=sql-server-ver15.

\section{Відомості про автора:}

\section{Федько Віктор Васильович}

кандидат фізико-математичних наук доцент доцент кафедри Харківського національного економічного університету ім. С. Кузнеця, Харків, Україна https://orcid.org/0000-0002-4146-5272
Information about the author:

Viktor Fedko

$\mathrm{PhD}$ Associate Professor

Senior Lecturer of Simon Kuznets Kharkiv National

University of Economics,

Kharkiv, Ukraine

https://orcid.org/0000-0002-4146-5272

\section{ИССЛЕДОВАНИЕ ЭФФЕКТИВНОСТИ ПРИМЕНЕНИЯ ТЕХНОЛОГИИ МАСНINE LEARNING SERVICES В ЗАДАЧАХ ПРОГНОЗИРОВАНИЯ}

\section{В.В. Федько}

Изложены и проанализированы результаты экспериметов по эффективности решения задач прогнозирования методами Machine Learning с применением технологии Machine Learning Services. Эта технология заключается в переносе проиессов обработки данных из компьютера клиента (как это реализовано в классической технологии Масһіпе Learning) на сервер, на котором хранятся данные. Исследования проводились путем сравнения затрат времени решения задач по каждой технологии при различных объемах данных. Результаты исследований показали, что применение технологии Machine Learning Services имеет в два раза лучшие показатели на количестве данных более полутора миллионов записей.

Ключевые слова: Machine Learning, хранилище данных, SQL Server, Python, Machine Learning Services, nроизводительность приложения.

\section{PERFORMANCE STUDY OF APPLICATION EFFICIENCY OF MACHINE LEARNING SERVICES TECHNOLOGY IN PREDICTION TASKS}

\section{Fedko}

Implementation of data analysis in the interactive mode imposes strict limits on the time during which the transition from one value of the analysis parameters to another. Machine Learning Services technology developed by Microsoft aims to reduce the problem of data processing time. The paper presents and analyses the results of experiments on the effectiveness of solving forecasting problems by Machine Learning methods using Machine Learning Services technology. It consists in transferring data processing processes from the client computer (as implemented in the classic Machine Learning technology) to the server where the data is stored. The research was conducted by comparing the time spent solving problems for each technology with different amounts of data. The research uses data from an imaginary network of kiosks selling a variety of bakery products. A script was used to populate the Sales operational data table. With its help, the data on the results of sales of goods of each manufacturer in each kiosk are filled with pseudo-random numbers within reasonable limits. A data warehouse with a star scheme was used for data analysis. It was filled with data transferred from the operational database. Because it is necessary to compare the time of solving the problem of forecasting by two technologies - classical and MLS, which are implemented in Python and SQL languages, Azure Data Studio was chosen as the development environment. In addition to database tools, it allows you to easily switch from one language to another. Studies have shown: 1) the total time for solving forecasting problems by ML methods in the case of MLS technology is twice as short as in classical technology; 2) a significant gain in time is manifested in the case when the number of records exceeds 1.5 million. In the case of a smaller number of data, the benefits are insignificant; 3) the main contribution to the time of solving forecasting problems by ML methods is the transfer of data from the database to the client's computer; 4) the dependence of the total time spent on solving the studied problems is well described by the linear dependence on the amount of processed data in both technologies. The research was conducted when the client and server were located on the same physical computer. Further similar research is of interest when the server is hosted on a remote computer or in the clouds. The results obtained should be taken into account when developing applications that implement ML methods.

Keywords: Machine Learning, Data Warehouse, SQL Server, Python, Machine Learning Services, application performance. 